\title{
Reduction of Dioxins and Furans Emission in Air and Soil Samples after Renovation Works at Ararat Dumpsite
}

\author{
Anahit Aleksandryan', Artak Khachatryan ${ }^{2}$, Petr Kukucka ${ }^{3}$, Petra Pribylova ${ }^{3}$, Pavel Cupr ${ }^{3}$, Katerina \\ Sebkova ${ }^{3}$ \\ ${ }^{1}$ Ministry of Nature Protection of the Republic of Armenia \\ Governmental Building 3, Republic Square, Yerevan, Republic of Armenia \\ anahit.aleksandryan@yahoo.com; \\ ${ }^{2}$ Environmental Monitoring and Information Center SNCO \\ 46 Charents Street, Yerevan, Republic of Armenia \\ khachart7@yahoo.com \\ ${ }^{3}$ RECETOX, Faculty of Science, Masaryk University \\ Kamenice 753/5, Brno, Czech Republic \\ kukucka@recetox.muni.cz; pribylova@ recetox.muni.cz; cupr@ recetox.muni.cz; sebkova@ recetox.muni.cz
}

\begin{abstract}
Due to the lack of sanitary landfills in Armenia, general unseparated wastes are disposed to dumpsites. Then in order to reduce their amounts and volumes uncontrolled burning of wastes occurs. As known, low-temperature burning of waste generates emissions of unintentionally produced dioxins and furans. At the selected pilot dumpsite of Ararat (Republic of Armenia) renovation works were performed, then followed infrastructure development, as well as implementation of best available technique and best environmental practice. The paper deals with data obtained through 2 monitoring campaigns, including analyses of samples of air and soil taken at the dumpsite area before and after renovation works. For PCDDs/PCDFs determination passive sampling was arranged and done using passive samplers installed at the selected site of Ararat urban dumpsite before and after renovation works. Collection of samples was done for the evaluation of the environmental situation ( 2 monitoring campaigns). The samples were analysed for PCDD/PCDFs at the laboratory of RECETOX (Masaryk University, Brno, Czech Republic) as an external laboratory. The entire procedure was executed in accordance to SOP provided by the RECETOX. Considering findings of the First and Second Monitoring Campaigns, we identified some sampling points that can be compared. Thus, air samples 10001, 10002 and 10003 can be compared with 20001, 20002 and 20003 accordingly. The following observations were done. For air samples decrease of PCDDs/PCDFs concentration made from 28 to 65 times. For soil samples PCDDs/PCDFs concentration decreased 304-393 times.
\end{abstract}

Keywords: Dioxins; Furans; Emissions; BAT/BEP; Sampling; Monitoring.

\section{Introduction}

Likewise other countries, in Armenia almost all industrial and municipal wastes are disposed to landfills without separation and open burning of waste is common, because it is the cheapest, easiest, most sanitary means of volume reduction and disposal of combustible materials, though the incomplete burning is not efficient to reduce the sanitary risks due to the pathogens present in the waste. In urban areas, it can be expected that municipal waste is mainly composed by food residues, packaging of goods and some hazardous wastes (such as batteries and electronic devices), whereas in suburban or rural zone these shares can decrease in favor of country specific agricultural waste [1].

Currently, the quality and coverage of waste collection in Armenia is better in urban centers than in rural areas, but generally the collection and transportation equipment are outdated and insufficient to deliver a regular service. At the same time, minimal wastes sorting (separation at source) is practiced. There is no plant for waste treatment, recycling, utilization, and the appropriate specialized polygons for hazardous wastes are lacking $[2 ; 3]$.

"Implementation of BAT and BEP for Reduction of UP-POPs Releases from Open Burning Sources" project was implemented by the Ministry of Nature Protection of the Republic of Armenia and the United Nations Industrial Development Organization (UNIDO) with the financial assistance of the Global Environment Facility (GEF). The Project Objective was to reduce releases of unintentionally produced (UP) persistent organic pollutants (POPs) in open burning sources in Armenia 
through introduction of Best Available Techniques and Best Environmental Practices (BAT/BEP) and create capacity within the Government and private sector on BAT and BEP implementation.

Pilot demonstration activities addressed a selected dumpsite in the Ararat Municipality. The local government in Ararat was the key stakeholder in implementing BAT/BEP and making a shift from burning of waste to recycling or re-use [4].

Comprehensive assessment of Ararat urban dumpsite was done through initial assessment of streams and types of generated waste. A detailed study was performed on frequency of waste generation, geographic distribution of near-by settlements, schemes of waste collection, and the representative sample was taken.

In accordance with the Plan of Sampling all wastes were sorted (separated) into the following 7 groups: Plastic waste; Plastic bags/ packaging; Glass; Metals; Paper and cardboard; Textile; Remnants (mainly, organic wastes).

The geological assessment of the site was also done. Sampling was done and analyses of soil samples for the content of POPs were performed in 2016-2018 [4; 5].

\section{Materials and Methods}

In order to reveal current situation of the Ararat dumping site, and for further comparison of the results two Monitoring Campaigns were conducted: before and after renovation works at the selected site.

For determination of polychlorinated dibenzodioxins (PCDDs) and polychlorinated dibenzofurans (PCDFs) passive sampling was arranged and done using passive samplers installed at the selected site of Ararat urban dumpsite before and after renovation works and development of appropriate landfill infrastructure.

The samples were analyzed for PCDD/PCDFs at the laboratory of Research Center for Toxic Compounds in the Environment (RECETOX) of Masaryk University, Brno, Czech Republic as an external laboratory. The entire procedure was executed in accordance to SOP provided by the RECETOX.

For the analysis of ambient air passive samplers (or better of a sorbent made from cleaned polyurethane foam disks, PUF disks), SOP-LSA-031 (US EPA 1613B) method was used. A gas chromatograph coupled to a high-resolution mass spectrometer (Thermo Scientific dual GC Trace 1310 and HRMS DFS) was used for the separation and quantification of the analytes.

For the analyses of collected soil samples for PCDDs/Fs a modified US EPA 1613B method was used. A gas chromatograph coupled to a high-resolution mass spectrometer (Thermo-Scientific dual GC Trace 1310 and HRMS DFS) were used for the separation and quantification of the analytes.

\section{Results and Discussion}

Renovation works were carried out at Ararat urban dumpsite that was earlier characterized by open burning routine practice and considered to be a source of Dioxins/ Furans emissions. Renovation and infrastructure development at the site allowed to strengthen the capacity to eliminate Dioxins/ Furans releases [6].

\subsection{Results of the First Monitoring Campaign (Monitoring I)}

The following observations could be seen while investigating the obtained results of passive sampling of the air: PCDDs and PCDFs are present in all 3 samples (Figure 1);

- $\quad$ Variation of $\sum P C D D$ is in the range of 2.111-10.91 ng/sample;

- $\quad$ Variation of $\sum P C D F$ is in the range of 2.8-7.15 ng/sample;

- $\quad \sum$ PCDD Tetra + Penta is in the range of $80 \%-98.6 \%$;

- $\quad \sum \mathrm{PCDF}$ Tetra + Penta is in the range of $89.5 \%-100 \%$.

The following observations can be done investigating the results of laboratory analysis of soil samples:- $\quad$ PCDDs were identified in 3 out of 5 soil samples

- $\quad$ PCDFs were identified in all 5 soil samples (Figure 2);

- $\quad$ Variation of $\sum P C D D$ is in the range of $0.846-2.5 \mathrm{ng} / \mathrm{g}$ of dry matter;

- $\quad$ Variation of $\sum P C D F$ is in the range of $0.376-1.274 \mathrm{ng} / \mathrm{g}$ of dry matter;

- $\quad \sum \mathrm{PCDF}$ Tetra + Penta is in the range of $69 \%-93 \%$;

- $\quad \quad \quad \quad \quad \mathrm{PCDD}$ Tetra + Penta is in the range of $33 \%-44 \%$. 
As far as the comparison between previous and current monitoring campaigns is concerned, the following correlations were found. Despite the fact that during previous monitoring campaigns soil samples were analyzed for determination of residual quantities of organochlorine pesticides and PCBs, rather than PCDDs and PCDFs there is still obvious correlation:

- $\quad$ in $87,5 \%$ of all previous soil samples $\sum$ PCBs Tetra + Penta was in the range of $81 \%-95,3 \%$

- $\quad$ in $100 \%$ of all current soil samples $\sum$ PCDF Tetra + Penta is in the range of $69 \%-93 \%$

- $\quad$ in $100 \%$ of all current air samples $\sum$ PCDD Tetra + Penta is in the range of $80 \%-98,6 \%$

- $\quad$ in $100 \%$ of all current air samples $\sum \mathrm{PCDF}$ Tetra + Penta is in the range of $89,5 \%-100 \%$.

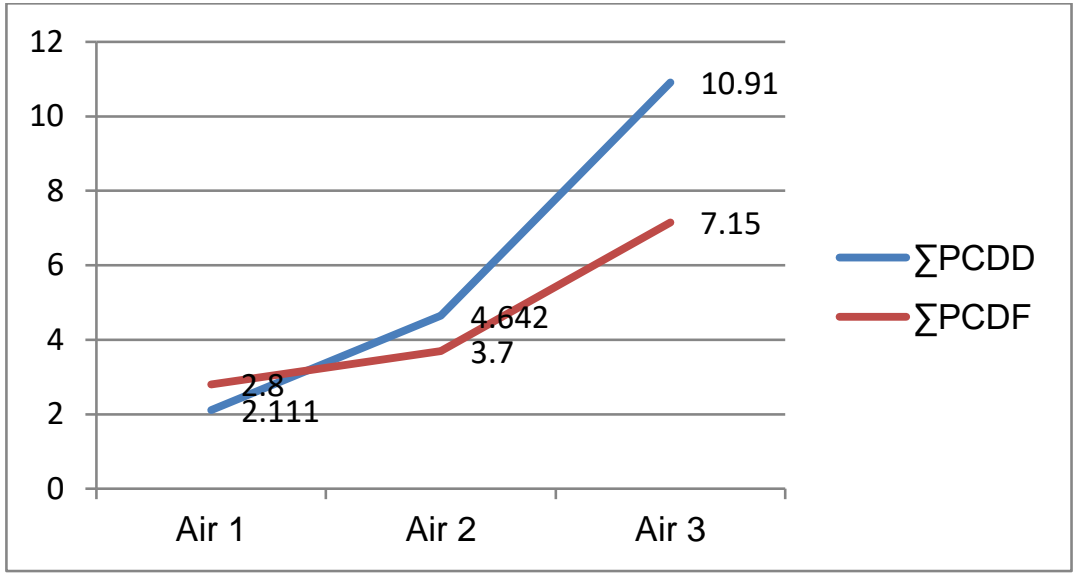

Fig. 1: Dioxins and Furans content in air samples, Monitoring Campaign I.

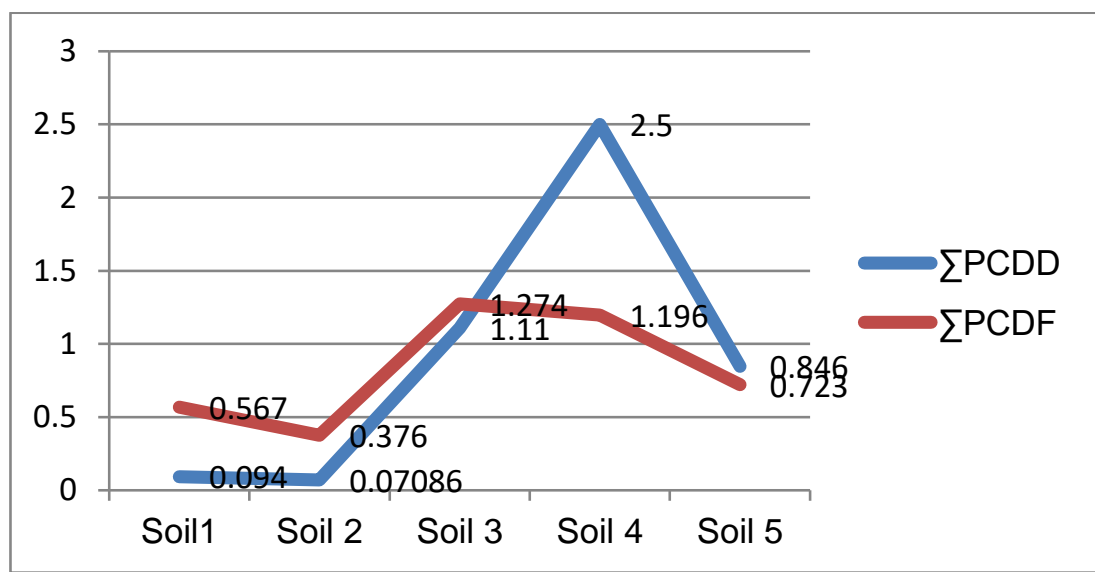

Fig. 2: Dioxins and Furans content in soil samples from the dumpsite area, Monitoring Campaign I.

\subsection{Results of the Second Monitoring Campaign (Monitoring II)}

Results obtained during the second Monitoring Campaign are presented as Figures 3-6 below. 


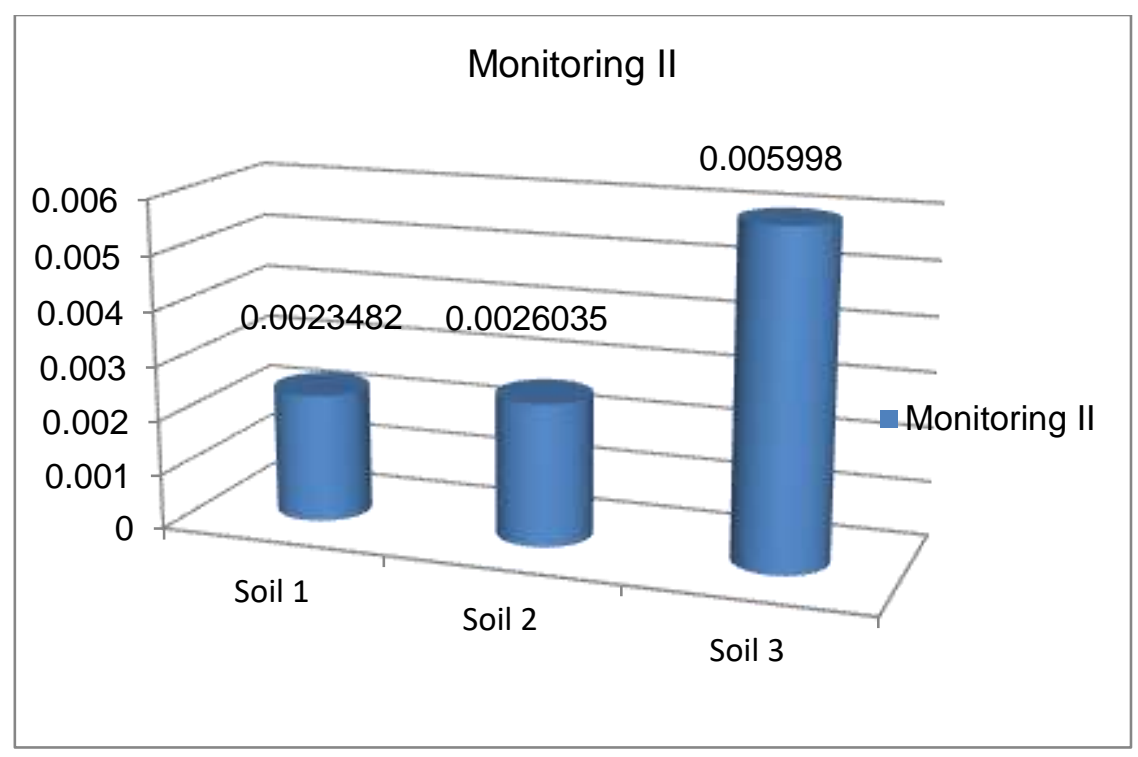

Fig. 3: Dioxins content in soil samples, Monitoring Campaign II.

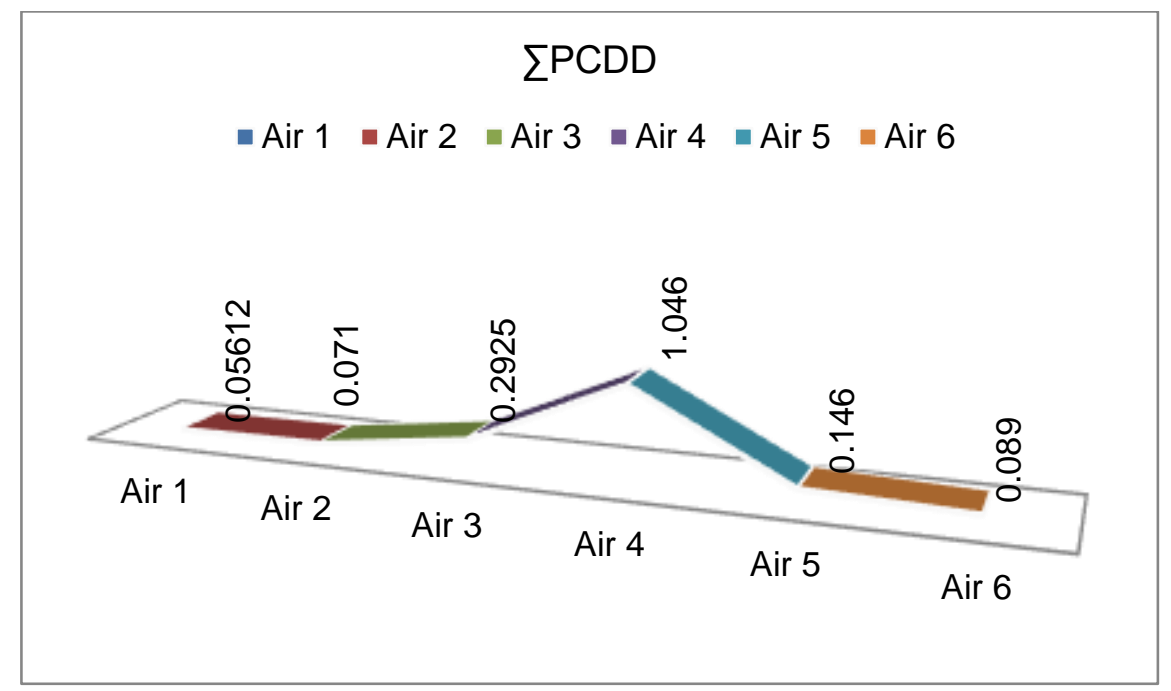

Fig. 4: Dioxins content in air samples, Monitoring Campaign II. 


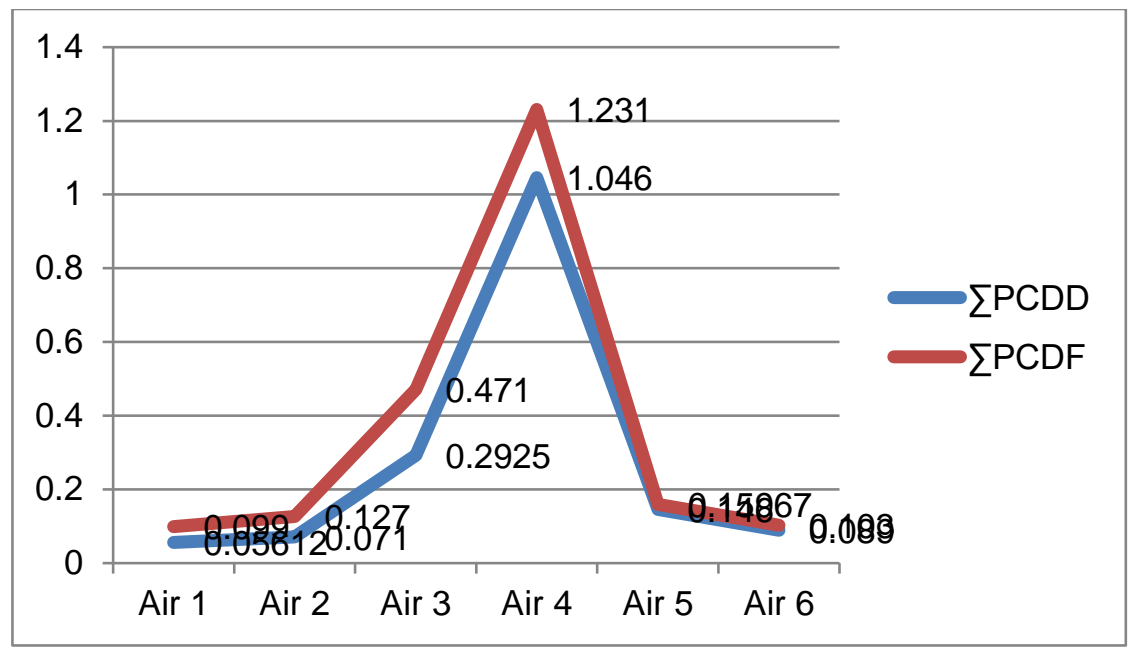

Fig. 5: Results of analyses of air samples for Dioxins and Furans, Monitoring Campaign II.

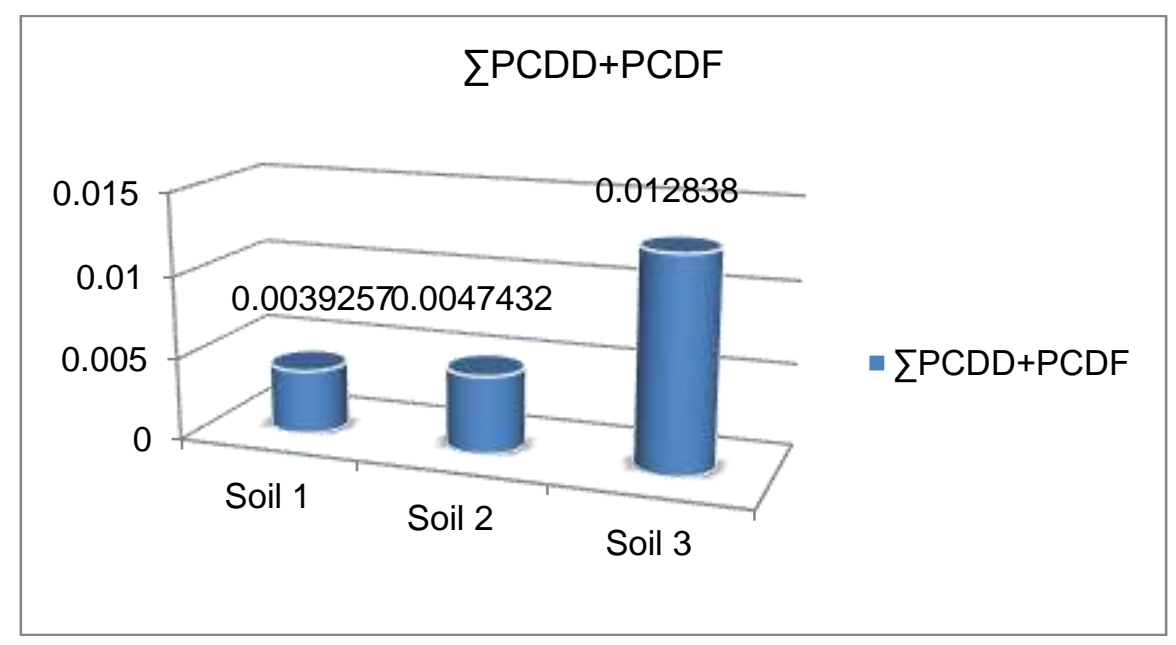

Fig. 6. Dioxins and Furans summary content in soil samples, Monitoring Campaign II.

\subsection{Comparison of data obtained during Monitoring Campaigns I and II}

Comparison of data obtained due to laboratory analyses of samples of air and soil during two monitoring campaigns is presented in Figures 7-10. 


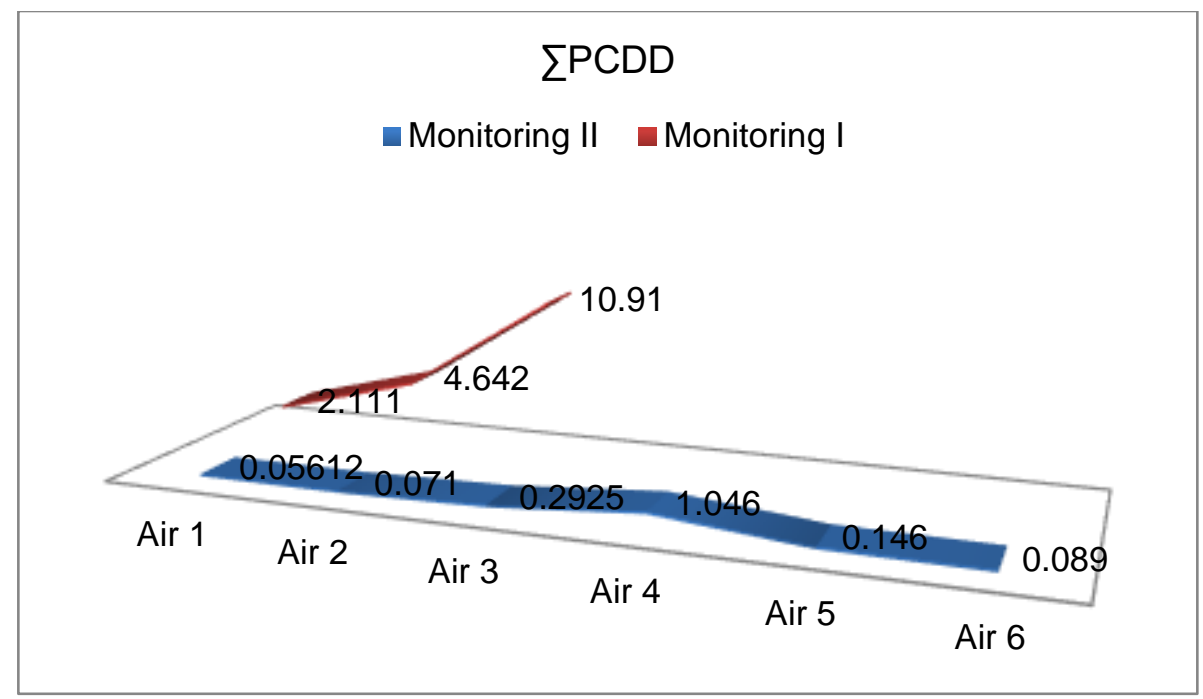

Fig. 7: Comparison of data obtained during Monitoring Campaigns I and II: analyses of air samples for PCDDs.

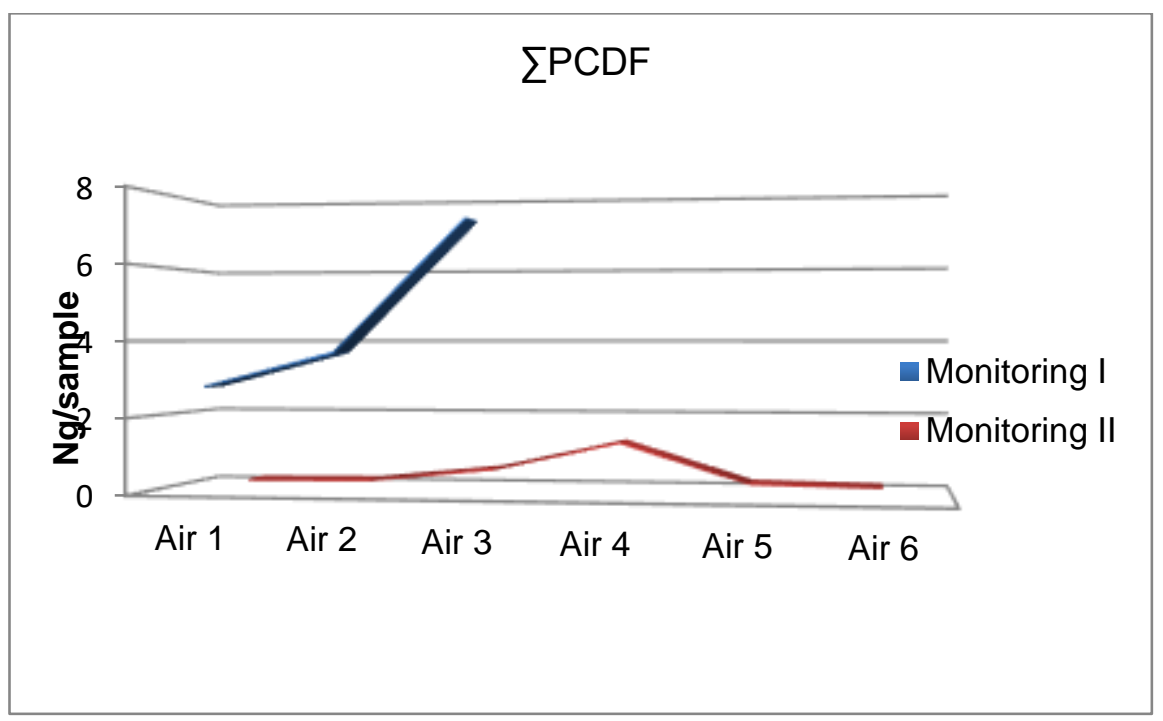

Fig. 8. Comparison of data obtained during Monitoring Campaigns I and II: analyses of air samples for PCDFs. 


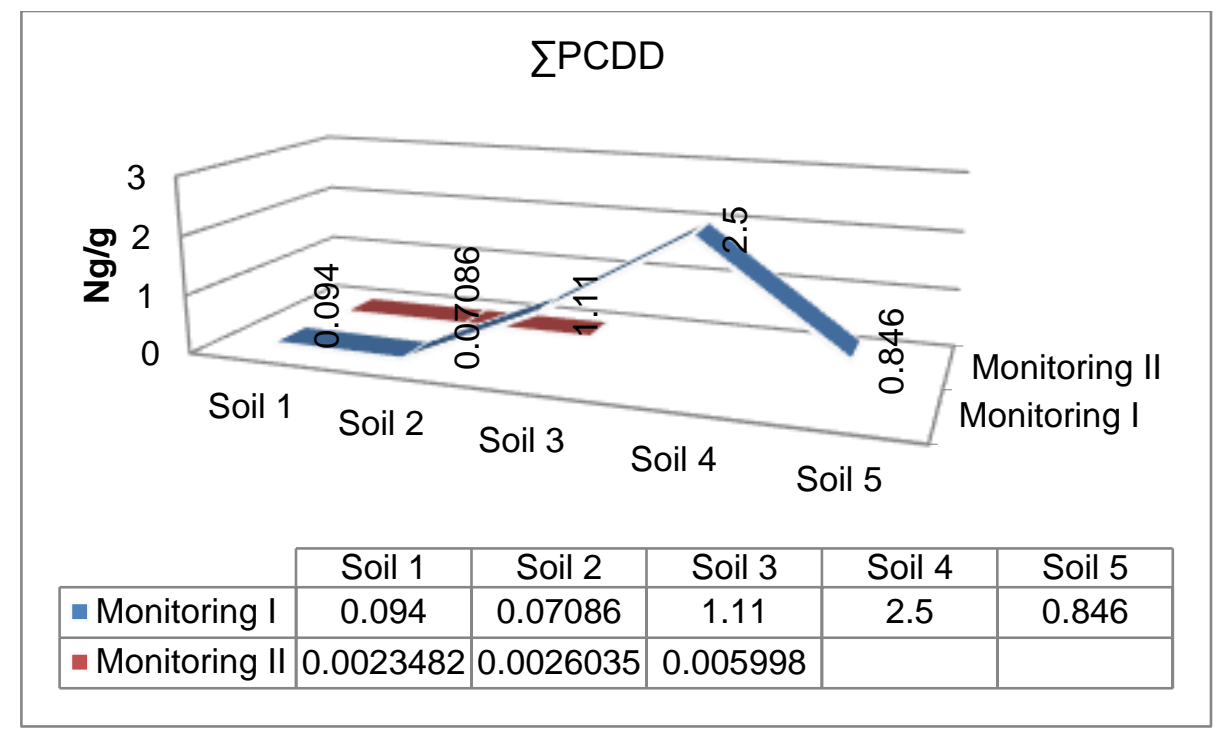

Fig. 9: Comparison of data on analyses of soil samples for Dioxins obtained during Monitoring Campaigns I and II.

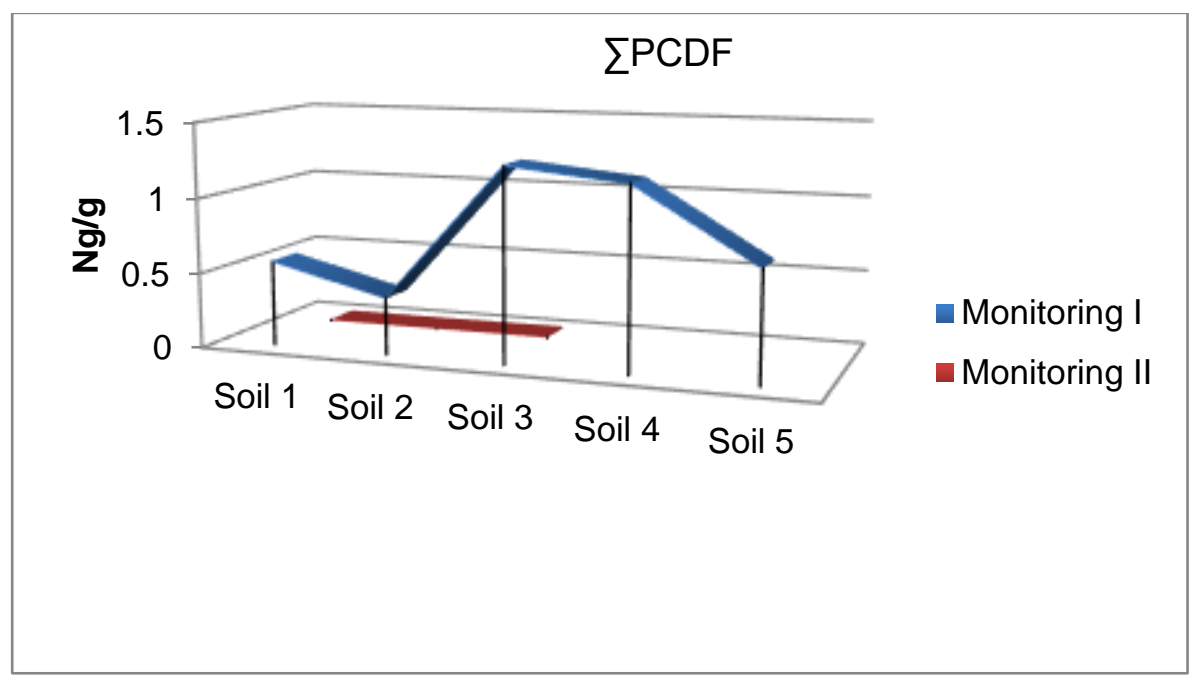

Fig. 10: Comparison of data on analyses of soil samples for Furans obtained during Monitoring Campaigns I and II.

\section{Conclusion}

If we take a look at findings of the First and Second Monitoring Campaigns, we will find some sampling points that can be compared. Thus Air samples 10001, 10002 and 10003 can be compared with 20001, 20002 and 20003 accordingly. If we do so we will see following:

For Air

- $\quad \quad \quad$ PCDD in sample 10001= $2.111 \mathrm{ng} / \mathrm{sample}$ meanwhile $\sum$ PCDD in sample 20001 $=0.05612 \mathrm{ng} / \mathrm{sample.} \mathrm{There} \mathrm{is}$ more than 30 times decrease of the concentration.

- $\quad \sum$ PCDD in sample 10002 $=4.642 \mathrm{ng} / \mathrm{sample}$ meanwhile $\sum$ PCDD in sample 20002 $=0.07085 \mathrm{ng} / \mathrm{sample.} \mathrm{There} \mathrm{is}$ more than 65 times decrease of the concentration. 
- $\quad \sum P C D D$ in sample $10003=10.91 \mathrm{ng} / \mathrm{sample}$ meanwhile $\sum$ PCDD in sample $20003=0.2925 \mathrm{ng} / \mathrm{sample}$. There is $\underline{\text { more }}$ than 37 times decrease of the concentration.

- $\quad \sum$ PCDF in sample $10001=2.8 \mathrm{ng} /$ sample meanwhile $\sum$ PCDD in sample $20001=0.09913 \mathrm{ng} / \mathrm{sample}$. There is $\underline{\text { more }}$ than 28 times decrease of the concentration.

- $\quad \sum$ PCDF in sample $10002=3.7 \mathrm{ng} /$ sample meanwhile $\sum$ PCDD in sample $20002=0.12722 \mathrm{ng} / \mathrm{sample}$. There is more than 29 times decrease of the concentration.

- $\quad \sum$ PCDF in sample $10003=7.15 \mathrm{ng} / \mathrm{sample}$ meanwhile $\sum$ PCDD in sample $20003=0.47122 \mathrm{ng} / \mathrm{sample}$. There is more than 15 times decrease of the concentration.

For Soil

- $\quad \sum$ PCDD (average concentration in samples Soil 1,2,3,4,5) $=0.924 \mathrm{ng} / \mathrm{g}$ meanwhile $\sum$ PCDD in soil sample 2_1 made $0.002348 \mathrm{ng} / \mathrm{g}$. The decrease of the concentration in soil made more than 393 times.

- $\quad \sum$ PCDF (average concentration in samples Soil 1,2,3,4,5) =0.8272 ng/g meanwhile $\sum$ PCDF in soil sample $2 \_1$ made $0.0027192 \mathrm{ng} / \mathrm{g}$. The decrease of the concentration in soil made more than 304 times.

- $\quad \sum \mathrm{PCDD}+\sum \mathrm{PCDF}$ (average concentration in samples Soil 1,2,3,4,5) =1.7512 ng/g meanwhile $\sum \mathrm{PCDD}+\sum \mathrm{PCDF}$ in soil sample 2_1 made $0.0050674 \mathrm{ng} / \mathrm{g}$. The decrease of the concentration in soil made more than 345 times.

\section{References}

[1] A. V. Aleksandryan and A. V. Khachatryan, "Releases of dioxins/furans as environmental challenge," in Proceedings of the XIII International Research and Practice Conference, Munich, Germany, 2016, pp. 44-48.

[2] A. Aleksandryan, V. Khachatryan, A. Khachatryan, and F. Petrosyan, "Waste Dumps as a Source of Dioxins and Furans," in Proceedings of the 28th Conference of the International Society for Environmental Epidemiology. Rome, Italy, 2016.

[3] A. Aleksandryan, A. Khachatryan, and F. Petrosyan, "Waste dumps as a source of dioxins and furans," in Proceedings of DIOXIN 2017 - 37th International Symposium on Halogenated Persistent Organic Pollutants (POPs), Vancouver, Canada, 2017, Abstract ID 099795.

[4] A. Aleksandryan, A. Khachatryan, R. Prokeš, P. Přibylová, and K. Šebková, "Implementation of BAT and BEP to Reduce Dioxins and Furans Emissions for Environmental Protection," in Proceedings of the $8^{T H}$ International Conference on Environmental Pollution and Remediation (ICEPR'18), Madrid, Spain, 2018.

[5] A. V., Aleksandryan, A. V. Khachatryan, A. Kočan, and K. Šebková, "Results of Analyses for PCDDs/PCDFs Emissions at Open Burning," in Proceedings of DIOXIN 2018, Kraków Abstracts Book: 38th International Symposium on halogenated Persistent Organic Pollutants \& 10th International PCB Workshop, 26 - 31 August 2018, Kraków, Poland. Gdańnsk University Press, Gdańnsk, 2018.

[6] A. V. Aleksandryan and A. V. Khachatryan, "Calculation of dioxins and furans emissions and their analyses in samples of air and soil: Ararat marz (Armenia)," in Proceedings of the 11th SETAC Asia-Pacific Meeting, Daegu, Korea, 2018. 